\title{
Larval size in Elysia stylifera is determined by extra-embryonic provisioning but not egg size
}

\author{
Richard M. Allen ${ }^{1, *}$, Patrick J. Krug ${ }^{2}$, Dustin J. Marshall ${ }^{1,3}$ \\ ${ }^{1}$ School of Biological Sciences, The University of Queensland, Brisbane, Queensland 4072, Australia \\ ${ }^{2}$ Department of Biological Sciences, California State University, Los Angeles, California 90032-8201, USA \\ ${ }^{3}$ Centre for Marine Studies, The University of Queensland, Brisbane, Queensland 4072, Australia
}

\begin{abstract}
Marine invertebrates that lay egg masses provision their offspring in a variety of ways, and in some groups, egg size is not the sole determinant of offspring size at independence. Supplemental, maternally derived resources, such as extra-embryonic nutrients, may increase offspring size without increasing egg size - options not available to broadcast spawners. Extra-embryonic nutrients, such as nurse eggs, can increase offspring size and performance, but little is known about other forms of larval nutrition. Larvae of the sea slug Elysia stylifera have access to intra- and extra-capsular resources in the egg mass prior to an obligate planktonic feeding period. We investigated the effects of maternal body size on egg size, capsule size, extra-capsular yolk (ECY), and fecundity, and how variance in these traits affected larval size at hatching. Larger mothers produced larger and more eggs, but larval size was unrelated to maternal size, egg size, or fecundity. Larval size instead depended upon the size of the egg capsule and amount of ECY available to each developing embryo: when capsule size was small, increasing ECY per larva increased larval size, and conversely, when ECY per larva was small, increasing capsule size increased larval size. Under theoretical considerations, ECY appears to supplement egg provisioning. Intra-capsular fluid and ECY add to the already diverse set of known mechanisms of offspring provisioning in marine invertebrates, and may provide insight into the factors affecting life-history evolution in marine invertebrates.
\end{abstract}

KEY WORDS: Offspring size $\cdot$ Egg mass - Egg capsules - Extra-capsular yolk - Maternal effect Life history $\cdot$ Gastropod $\cdot$ Clutch size

\section{INTRODUCTION}

The amount of resources mothers invest in their offspring is an important life-history trait. Marine invertebrates have long been a model study system for investigating divergent strategies of offspring investment, because closely related species often differ dramatically in the amount they invest in each offspring (Thorson 1950, Vance 1973). Two alternative provisioning strategies have repeatedly evolved in most major clades: planktotrophy, where offspring are obligated to feed on non-maternally derived resources in the plankton in order to metamorphose into the juvenile stage, and lecithotrophy, where mothers provide sufficient energy reserves for offspring to attain metamor- phic competence (Levin \& Bridges 1995). However, direct comparisons between these developmental alternatives are usually confounded by the many other differences that exist between species, complicating efforts to contrast alternative provisioning strategies.

Within a species, greater investment per offspring can increase fertilization success (Levitan 1993, Marshall et al. 2002), extend the larval swimming period in lecithotrophs, but reduce it in planktotrophs (Emlet et al. 1987, Levitan 1993, 2000, Emlet 1995, Marshall et al. 2002, Marshall \& Bolton 2007, Marshall \& Keough 2007), and improve offspring performance post-metamorphosis (Emlet \& Hoegh-Guldberg 1997, Moran \& Emlet 2001, Marshall et al. 2003, Allen et al. 2008). Maternal investment is generally reflected in the size 
of the offspring once they become independent of maternal nutrition (Marshall \& Keough 2007). Most studies on variation in maternal investment in marine organisms have examined broadcast-spawning taxa, in which maternal investment is largely limited to the energy content of eggs (e.g. Emlet et al. 1987, Levitan 2000, Marshall \& Keough 2007). However, marine animals such as gastropods, polychaetes, and asteroids may have brood chambers or benthic egg masses that provide additional opportunities to provision offspring (Strathmann 1995).

Egg masses usually consist of multiple embryos developing inside capsules within an outer casing (Pechenik, 1979, Klussmann-Kolb \& Wagele 2001). Egg masses as protective coverings are costly to produce, but may reduce mortality by keeping larvae out of the dangerous planktonic environment during development (Pechenik 1999). In addition, egg masses allow mothers to allocate extra-embryonic resources, such as intra-capsular fluid or albumen vesicles, extracapsular yolk (ECY), or nurse eggs, which may increase offspring size and performance (Spight 1976, Perron 1981, Boucher 1983, Chaparro et al. 1999, Moran \& Emlet 2001). For example, mothers of the snail Nucella ostrina provide developing embryos with unfertilized nurse eggs as additional nutrition, allowing larvae to complete development and hatch as crawl-away juveniles (Spight 1976). In N. ostrina, egg size is not a good predictor of hatching size, but the additional nutrients provided by nurse eggs are positively correlated with hatching size (Lloyd \& Gosselin 2007), which in turn is positively correlated with offspring performance (Moran \& Emlet 2001).

Consumption of nurse eggs occurs in many polychaetes and caenogastropods, but is unknown among opisthobranch gastropods (sea slugs). Instead, many opisthobranchs include nutritive material as intra-capsular albumen, and at least 2 major clades imbed ECY within the egg mass (Clark \& Jensen 1981, KlussmannKolb \& Wagele 2001, Krug 2009). Intra-capsular nutrients are costly to produce: in Conus, capsular fluid comprises $\sim 10$ to $12 \%$ of the total energy in a capsule (Perron 1981). Maternal investment in intra-capsular albumen is associated with lecithotrophy in the opisthobranch group Sacoglossa; veligers consume albumen during development, which may permit attainment of competence despite atypically small egg sizes (Clark \& Jensen 1981). In contrast, the benefits of extra-capsular provisioning are unknown. ECY has been proposed to (1) accelerate benthic development by shifting yolk out of the egg (Clark \& Jensen 1981); (2) permit flexibility in larval type (Clark et al. 1979, Thompson \& Salghetti-Drioli 1984); (3) render egg masses unpalatable and aposematic by containing toxins and colorful pigments (Paul \& Van Alstyne 1988,
Jensen 2001); or (4) increase the ratio of larval size to egg size (Boucher 1983, Krug 2009). A nutritional role for ECY is supported by observations that larvae may absorb ECY through the capsule wall, ingest ECY granules that enter their capsule, or ingest ECY after emerging from the capsule but before hatching from the egg mass (Boucher 1983, Thompson \& SalghettiDrioli 1984, Krug 2009).

A particular conundrum is why planktotrophic species with prolonged post-hatching larval phases incorporate ECY into their egg masses if ECY serves a nutritional role. As a life-history strategy, planktotrophy is thought to trade off maternal investment against fecundity, shifting the energetic burden of development from mother to offspring (Vance 1973, Strathmann 1985). Why then would mothers invest in ECY rather than produce more eggs? Increasing offspring size in planktotrophs may reduce planktonic development time or increase post-metamorphic size, and these benefits may account for maternal investment in ECY, if ECY does indeed increase offspring size at independence (Hadfield \& Miller 1987, Hart 1995). However, in the absences of data on the effect of ECY on offspring size at independence, this hypothesis remains untested.

The first goal of this study was to identify potential sources of variation in resource allocation to reproduction in the sacoglossan Elysia stylifera. As maternal body size is often related to maternal provisioning (Marshall \& Keough 2007), we tested whether maternal body size altered resource allocation to reproductive traits within the egg mass such as egg size, egg number, capsule size, and quantity of ECY. We then investigated how variation in such traits affected larval size at independence.

\section{MATERIALS AND METHODS}

Study species and site. Elysia stylifera (Jensen, 1997) is a sacoglossan opisthobranch known from Australia (present study and original description) and French Polynesia (P. Krug \& R. Ellingson unpubl. data). Jensen (1997) placed this species in Elysiella along with E. pusilla (Bergh, 1872) after Gosliner (1995) determined Elysiella was an invalid genus and a junior synonym of Elysia. Molecular phylogenetic studies confirm Gosliner (1995), finding no support for Elysiella as a separate genus, but instead, recovering E. pusilla and E. stylifera as sister species belonging to a basal group of Elysia spp. (P. Krug unpubl. data). Both E. stylifera and E. pusilla co-occur wherever E. stylifera has been collected. Their principal distinguishing characteristics are the presence of a penial stylet and thicker, larger parapodia in E. stylifera, and a transverse groove dividing the anterior foot in E. pusilla. 
Specimens were obtained by collecting the host alga Halimeda discoidea via snorkel in the shallow subtidal waters $(<5 \mathrm{~m})$ off Point Cartwright $\left(26^{\circ} 40.9^{\prime} \mathrm{S}\right.$, $\left.153^{\circ} 08.2^{\prime} \mathrm{E}\right)$ on the Sunshine Coast, Australia, during September and October of 2007. Algae was transported in thermally insulated tanks from the field site to the laboratory, where slugs were collected as they crawled off the alga. Elysia stylifera is a simultaneous hermaphrodite, but selfing is rare in opisthobranchs (Smolenksy et al. 2009). Fertilization occurs via hypodermic insemination anywhere on the body, and slugs can store sperm from copulation for at least $10 \mathrm{~d}$ (authors' obs.). Slugs deposit benthic egg masses on the host algae $H$. discoidea in the field, but in the laboratory, they readily deposited egg mass on Petri dishes. Some slugs laid multiple egg masses during the course of the experiment; however, data was only collected on the first egg mass laid in the laboratory for each mother.

In sacoglossan egg masses, each ovum is surrounded by a viscous matrix of nutritive albumen material enclosed within a membranous capsule; a string of jellyembedded capsules is then wound inside a tough outer membrane that forms a protective tube, and the tube is deposited as a flat, tight spiral in Elysia spp. (Clark et al. 1979, Clark \& Jensen 1981, Klussmann-Kolb \& Wagele 2001). The term 'egg' refers to uncleaved ova, 'embryo' to pre-veliger stages, 'capsule' to the spherical membrane surrounding each individual embryo and its albumen reserves, and 'egg mass' to the entire spiral comprising a string of encapsulated eggs and ECY inside the tough outer wall. In E. stylifera, the disc-shaped egg mass is $\sim 5 \mathrm{~mm}$ in diameter and $<1 \mathrm{~mm}$ thick, with a maximum 2 layers of egg capsules per unit area of egg mass. A ribbon of yellow/orangecolored ECY is also embedded in the jelly matrix surrounding the egg capsules, evenly distributed over the capsules.

Embryos develop inside the capsules, initially absorbing or consuming intra-capsular albumen as they mature into encapsulated veligers. Within an egg mass, ECY is consumed by veliger larvae, and by the time an egg mass begins hatching, little ECY remains. Larvae exit the egg mass and enter the plankton within a few hours of emergence from their individual capsules. The exact method by which larvae consume ECY in Elysia stylifera is unclear, but yolk ribbons gradually disappear while larvae complete their intracapsular development, and the larval digestive gland takes on the orange color of ECY prior to hatching from the capsule, indicating uptake.

Laboratory techniques and measurements. In the laboratory, individual slugs were placed in Petri dishes (90 mm diameter) with $30 \mathrm{ml}$ fresh $0.22 \mu \mathrm{m}$-filtered seawater (FSW). Dishes were held in an incubator at $25^{\circ} \mathrm{C}$, on a $14 \mathrm{~h}$ photoperiod (14 h light:10 h dark).
Water was changed daily, and no food was given to the slugs for the $7 \mathrm{~d}$ that we allowed for spawning. Freshly laid egg masses were carefully cut free of the Petri dish using a new scalpel blade. Both the egg mass and mother were imaged using a digital microscope camera (PixeLINK Capture SE Ver. 1.0). The sizes of eggs, capsules, larvae, egg masses, and mothers were measured using Image-Pro express version 5.1. Egg, capsule, and egg mass sizes were all measured as the 2-dimensional cross-sectional areas. At least 10 eggs, capsules, and larvae from each egg mass were measured and the averages of these measurements were used in analysis, where the average of the trait within a single egg mass (from a single mother) represents the unit of replication. Maternal body size was measured from the most anterior to posterior part of slugs fully outstretched during locomotion. We also took replicate counts from 3 haphazardly selected $1 \mathrm{~mm}^{2}$ sections of each egg mass and counted the number of eggs per section. We multiplied the average of the 3 counts by the total egg mass area to estimate the total number of eggs per mass. The average number of eggs from the 3 counts was also used to estimate eggs per $\mathrm{mm}^{2}$. ECY was measured as both the total area of cover per egg mass to estimate the amount of ECY mothers produce, and the amount of yolk per egg available for each developing embryo (ECY ind ${ }^{-1}$ ).

The total cover of yolk per egg mass was estimated from the digital images by measuring the cover of yellow/orange substances within each mass. However, eggs are similar in color to ECY and could not be differentiated by the image analysis software; therefore, we subtracted the total area of egg cover from the total yellow/orange-colored area in each image giving an estimate of total ECY cover. The size of larvae was measured at hatching as the maximum larval shell dimension.

The number of females that laid egg masses was 25. Therefore, the starting replication was $\mathrm{n}=25$ for each trait. However, on 7 occasions, eggs had begun to cleave before measurements were taken. No eggs were measured in 4 of these 7 egg masses because no eggs were found uncleaved. The other 3 masses that had some cleaved eggs were measured and used in analyses; however, our confidence in their accuracy is reduced because <5 eggs were measured in each mass. Therefore, $\mathrm{n}=21$ for average egg size measurements. One egg mass was damaged during removal from the Petri dish, and while the embryos within developed normally, we were unable to get accurate data for egg number, eggs per $\mathrm{mm}^{2}$, or egg mass size, so $\mathrm{n}=24$ for these 3 traits. ECY was estimated at a later date to the other traits, during which time the digital images for 9 masses were lost due to computer error; consequently, traits of ECY were limited to $n=15$. 
Statistical analysis. All data were checked to meet the assumptions of the particular statistical analysis. Where these assumptions were not met (egg mass size, egg density, total ECY, and ECY ind.$^{-1}$ had skewed distributions), the data were transformed accordingly. Mass size, egg density, and ECY ind. ${ }^{-1}$ were transformed to the fourth root, and total ECY square-root transformed for analyses to improve their distribution. All data were treated as continuous factors.

We used a multiple regression to determine the relative contribution of egg size, capsule size, and ECY ind. ${ }^{-1}$ on hatching size of larvae. The full multiple regression model showed mutlicolinearity, so we used a forward stepwise method for model reduction (using partial $F$ of 0.15 for removing terms) and found egg size was removed from the model (Quinn \& Keough 2002, p. 112-114). We tested the effects of egg size on larval size as a single factor and found no variance in larval size was explained by egg size $\left(F_{1,19}=0.003, \mathrm{p}=\right.$ 0.960 ). Therefore, we performed a multiple regression for the effects of capsule size and ECY on larval size. The original multiple regression containing capsule size and ECY ind..$^{-1}$ showed low tolerance (tolerance $<0.1$ ). We then refitted the model after centering both capsule size and ECY ind. ${ }^{-1}$ (Quinn \& Keough 2002, p. 112-114).

Linear regression analyses were used to test specific hypotheses about the relationships between maternal body size and provisioning within egg masses that were not included in the multiple regression above. We also used linear regression to test hypotheses about the spacing of eggs within egg masses.

\section{RESULTS}

Approximately $50 \%$ of field caught slugs laid egg masses within $7 \mathrm{~d}$ of collection. Five to $7 \mathrm{~d}$ after egg masses were laid, $>95 \%$ of eggs had developed and hatched as free-swimming veliger larvae. Eggs occupied a relatively small volume of each capsule (Table 1 ). The average coverage of an egg mass with ECY was $~ 25 \%$ (Table 1). By comparing coefficients of variation, egg and larval size were less variable among slugs in the population than other egg mass traits (Table 1). Variation in egg size and capsule size was slightly greater among egg masses than within egg masses, but when we examined variation in larval size at independence, this pattern was reversed: larval size was slightly more variable within egg masses compared to the little variation in larval size among egg masses (Table 1).

\section{Maternal body size effects}

Maternal body size was significantly related to egg size $\left(F_{1,13}=13.585, \mathrm{p}=0.002, \mathrm{R}^{2}=0.417 ;\right.$ Fig. $\left.1 \mathrm{~A}\right)$, egg mass size $\left(F_{1,22}=5.236, \mathrm{p}=0.032, \mathrm{R}^{2}=0.192 ;\right.$ Fig. $\left.1 \mathrm{~B}\right)$, and the number of eggs per egg mass $\left(F_{1,22}=5.191, \mathrm{p}=\right.$ $0.033, R^{2}=0.488$; Fig. $1 C$ ). According to our regressions, doubling maternal body size resulted in a nearly $40 \%$ increase in the average cross-sectional area of each egg (Fig. 1A), a $200 \%$ increase in the size of egg masses (Fig. 1B) and a $400 \%$ increase in the number of eggs per mass (Fig. 1C). There was a trend for larger mothers to produce egg masses with more ECY, but this result was marginally non-significant $\left(F_{1,13}=\right.$ 4.250, $\mathrm{p}=0.060$; Fig. 1D). Maternal body size was not significantly related to capsule size $\left(F_{1,23}=0.075, \mathrm{p}=\right.$ $0.787)$, ECY ind. ${ }^{-1}\left(F_{1,13}=3.191, \mathrm{p}=0.097\right)$, larval size $\left(F_{1,23}=0.245, \mathrm{p}=0.625\right)$, or eggs per $\mathrm{mm}^{2}\left(F_{1,22}=0.233\right.$, $\mathrm{p}=0.634)$.

\section{Maternal provisioning effects on larval size}

Egg size was not related to larval size $\left(F_{1,19}=\right.$ $0.003, \mathrm{p}=0.960$ ). However, capsule size, amount of

Table 1. Elysia stylifera. Descriptive statistics for egg mass traits including mean, standard error (SE), coefficient of variation (CV) among slugs, and mean CV within slugs. Where only one measure of a trait was available per slug (mass), CV is indicated as not available (N/A)

\begin{tabular}{|c|c|c|c|c|c|}
\hline Trait & $\mathrm{n}$ & Mean & $\pm \mathrm{SE}$ & Among slug CV & $\begin{array}{l}\text { Mean within } \\
\text { egg mass CV }\end{array}$ \\
\hline Maternal size $(\mathrm{mm})$ & 25 & 14.423 & 0.542 & 0.188 & N/A \\
\hline Egg size $\left(\mu m^{2}\right)$ & 21 & 3979.235 & 81.568 & 0.094 & 0.080 \\
\hline Capsule size $\left(\mu m^{2}\right)$ & 25 & 14405.894 & 359.904 & 0.125 & 0.111 \\
\hline Total extra-capsular yolk $\left(\mathrm{mm}^{2}\right)$ & 15 & 5.045 & 0.756 & 0.581 & N/A \\
\hline Extra-capsular yolk per egg $\left(\mathrm{mm}^{2}\right)$ & 15 & 0.052 & 0.008 & 0.612 & N/A \\
\hline Mass size $\left(\mathrm{mm}^{2}\right)$ & 24 & 19.331 & 2.733 & 0.693 & N/A \\
\hline Number of eggs & 24 & 1935.374 & 289.811 & 0.734 & N/A \\
\hline Eggs per $\mathrm{mm}^{2}$ & 24 & 100.631 & 5.077 & 0.247 & N/A \\
\hline Larval size $(\mu \mathrm{m})$ & 25 & 130.085 & 1.088 & 0.042 & 0.048 \\
\hline
\end{tabular}



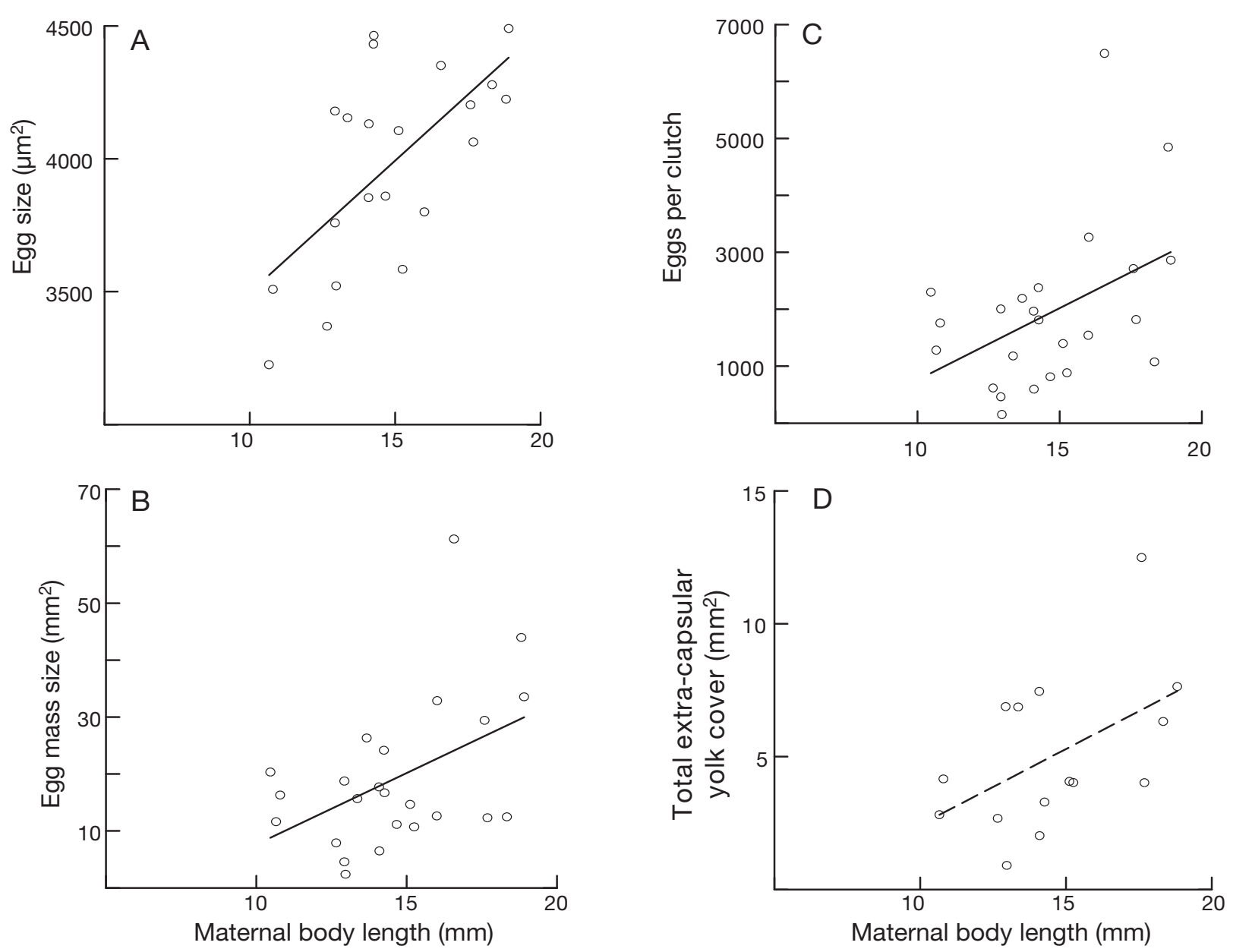

Fig. 1. Elysia stylifera. Effects of maternal body size on reproductive characteristics. Best-fit line from a linear regression for the relationship between maternal body size and (A) egg size (measured as cross sectional area); (B) egg mass size; (C) number of eggs per mass; and (d) total extra-capsular yolk per egg mass. Relationships in (A), (B), and (C) are significant to $\mathrm{p}<0.05$; (D) was borderline significant $(\mathrm{p}=0.060)$, indicated by dashed line. Each data point represents the reproductive characteristics of an individual slug

Table 2. Elysia stylifera. (a) Effects of capsule size and extra-capsular yolk on larval size at hatching and multiple regression results. Extra-capsular yolk was measured as amount of extra-capsular yolk per egg. Capsule size was measured as cross-sectional area. Egg size did not affect larval size and was omitted from the model. Std coeff.: standardized coefficient; $t$ statistic: Student's $t$-test

\begin{tabular}{|c|c|c|c|c|c|c|}
\hline $\begin{array}{l}\text { (a) Effects model } \\
\text { Coefficient }\end{array}$ & Estimate & $\pm \mathrm{SE}$ & Std coeff. & Tolerance & $t$ & $\mathrm{p}$-value \\
\hline Constant & 130.906 & 0.860 & $<0.001$ & & 152.168 & $<0.001$ \\
\hline Capsule size & 0.001 & 0.001 & 0.571 & 0.981 & 2.833 & 0.016 \\
\hline Extra-capsular yolk & 37.23 & 16.591 & 0.594 & 0.569 & 2.244 & 0.046 \\
\hline Capsule size $\times$ Extra-capsular yolk & 0.026 & 0.011 & -0.626 & 0.565 & -2.359 & 0.038 \\
\hline $\begin{array}{l}\text { (b) Multiple regression }\left(R^{2}=0.561\right) \\
\text { Source }\end{array}$ & $\mathrm{df}$ & MS & $F$ & $\mathrm{p}$-value & & \\
\hline Regression & 3 & 50.397 & 4.694 & 0.024 & & \\
\hline Residual & 11 & 10.736 & & & & \\
\hline
\end{tabular}


ECY per offspring, and the interaction between these 2 factors significantly affected larval size (Table 2). Increasing both the size of capsules and the amount of ECY available to each developing embryo increased larval size, but the increase in larval size was dependent on the amount of each source of nutrition (Fig. 2). When embryos developed in small capsules, larval size increased as more ECY was provided. Similarly, when embryos receive only a small portion of ECY, larval size increased when capsule size was increased. However, larvae that received large amounts of ECY or were in large capsules did not benefit from a further increase in the other variable.

\section{Factors affecting the spacing of eggs within egg masses}

When the size of egg capsules increased, the number of developing embryos per $\mathrm{mm}^{2}$ significantly decreased $\left(F_{1,22}=7.551, \mathrm{p}=0.012, \mathrm{R}^{2}=0.256\right.$; Fig. 3$)$. Neither egg size nor egg mass size significantly affected the number of eggs per $\mathrm{mm}^{2}$ (egg size: $F_{1,19}=$ $0.061, \mathrm{p}=0.807$; egg mass size: $F_{1,22}=1.020, \mathrm{p}=0.324$ ).

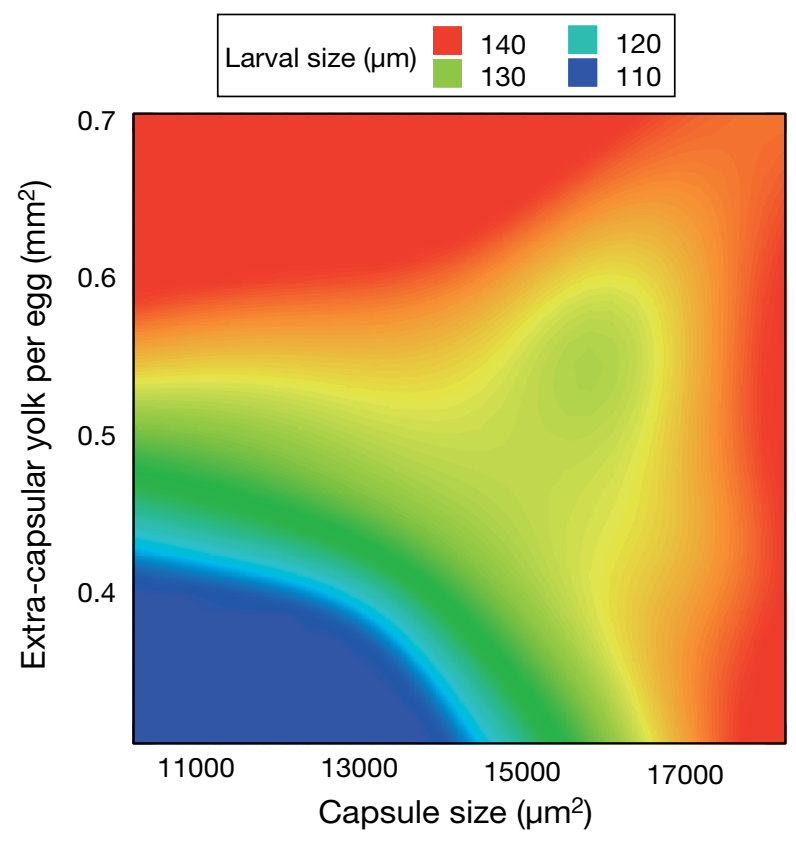

Fig. 2. Elysia stylifera. Capsule size and extra-capsular yolk contributions to larval size. Extra-capsular yolk is represented as extra-capsular yolk (ECY) per egg and transformed to the 4 th root. The color-contour shows the size of larvae that are produced at each level of combinations of capsule size and ECY per egg. Key shows larval size and corresponding color

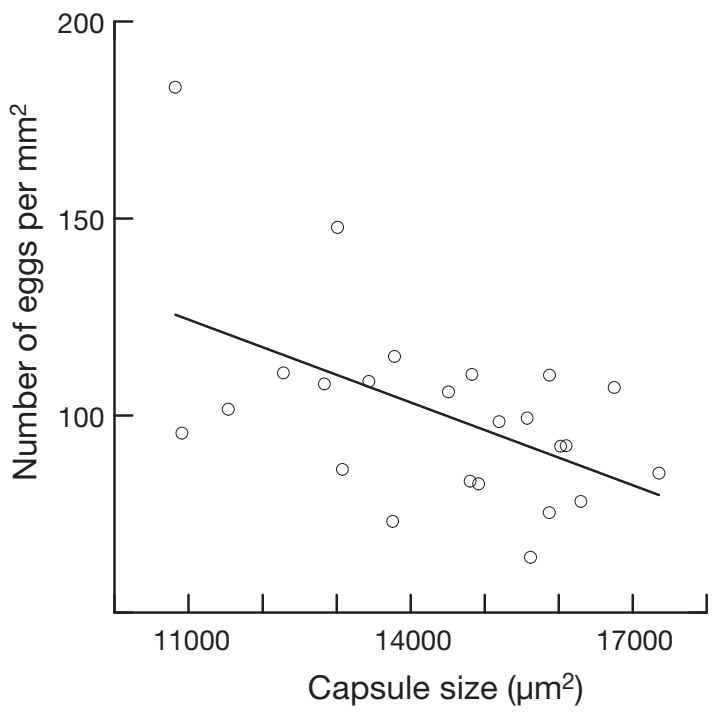

Fig. 3. Elysia stylifera. Best-fit line from linear regressions where egg capsule size was significantly related to the number of eggs per $\mathrm{mm}^{2}$. Each data point represents a single egg mass; trait of interest within each egg mass expressed on the axes

\section{DISCUSSION}

\section{Maternal provisioning per offspring}

In Elysia stylifera, there was a significant, positive relationship between maternal body size and egg size, but larval size at hatching was related to neither maternal body size nor egg size. Larval size was instead dependent on capsule size and the amount of ECY per developing embryo. Previous studies on other marine invertebrates have found positive relationships between maternal size and offspring size (Marshall \& Keough 2008), including opisthobranchs (Ito 1997). In turn, increasing offspring size provides a range of benefits to the offspring (Levitan 1993, Emlet \& HoeghGuldberg 1997, Moran \& Emlet 2001, Marshall et al. 2002, 2003, Marshall \& Keough 2008). For example, larger eggs are more likely to be fertilized in spermlimited conditions in free-spawners (Levitan 1993, Marshall et al. 2002). Larger eggs can become larger larvae (Hadfield \& Miller 1987, George et al. 1990, Hart 1995), and larger planktotrophic larvae have a shorter planktonic period that reduces larval mortality (Emlet et al. 1987, Emlet 1995, Levitan 2000). Larger larvae can also have higher post-metamorphic performance (Moran \& Emlet 2001, Marshall et al. 2003). However, in E. stylifera there was no apparent benefit of increased egg size on offspring size. First, increasing target size for sperm is unlikely, because fertilization is internal. Second, there was no effect of egg size on larval size, so larger eggs would not be expected to 
decrease planktonic development time, and may also not carry-over and affect post-metamorphic performance (Marshall \& Keough 2008). Interestingly, in the opisthobranch Haloa japonica, egg size is not correlated with larval size, but larvae developing from bigger eggs are more resistant to starvation in the plankton (Ito 1997), suggesting that although larvae were not bigger, there was an energetic benefit in coming from large eggs. Our data supports Ito (1997) in that egg size did not influence larval size, but we considered other sources of maternal provisioning that could affect larval size: capsular size and ECY.

Both capsule size and per-embryo quantity of ECY increased larval size at hatching, but in an interdependent manner. ECY increased larval size but only when capsule size was small; when capsules were large, additional ECY did not increase larval size further. Similarly, capsule size only increased larval size when little ECY was provided. Our results suggest that larval size in Elysia stylifera reaches a maximum size as a result of extra-embryonic provisioning: beyond this maximum, neither source of provisioning increases offspring size and may represent an upper size limit for this species. The consequences of increasing larval size are not known for this species, but based on theory and studies of larval size effects in other marine taxa, we predict that larger larvae may spend less time feeding in the plankton prior to metamorphosis and therefore suffer less planktonic mortality (Vance 1973, Levitan 2000). In addition, larval size can affect postmetamorphic performance, but these effects are more commonly attributed to species with non-feeding larvae (Hart 1995, Emlet \& Hoegh Guldberg 1997, Marshall et al. 2003, 2006). The potential for extra-embryonic nutrients in E. stylifera to significantly affect later life-history traits may be similar to the importance of nurse eggs to juvenile performance in Nucella ostrina (Moran \& Emlet 2001, Lloyd \& Gosselin 2007).

\section{Maternal provisioning per egg mass}

Clutch size is a particularly important life-history trait, because maternal fitness is the product of the number of offspring that reach reproductive maturity. In Elysia stylifera, larger mothers produced significantly larger egg masses that contained more eggs and ECY. A positive relationship between maternal body size and clutch size has been reported in other marine invertebrates (Spight \& Emlen 1976, Levin 1986, George 1994, Bridges \& Heppell 1996). The allometric scaling of reproductive traits with maternal body size is common because the volume of reproductive tissues is greater in larger mothers (Reiss 1989, Kiorboe \& Sabatini 1995, Bridges \& Heppell 1996). In addition, when larger mothers are more fecund, the relationship is often coupled with the nutritional state of mothers: larger mothers often have better nutrition (Spight \& Emlen 1976, Levin 1986, George 1994). Therefore, the increase in egg number and total ECY in E. stylifera may be the result of larger mothers having better nutrition that generally enables more resources to be spent on reproduction.

The positive relationship between maternal body size and number of eggs per mass was also coupled with egg size: larger mothers produced larger eggs. Such a trend is known in other marine invertebrates (Willows 1987, Dugan et al. 1991, Chaparro et al. 1999, Marshall et al. 2008). The Parker \& Begon (1986) model has been used to explain why some mothers increase egg size with increasing fecundity. The model shows that when mothers increase clutch size, sibling competition also increases and, therefore, mothers compensate for the fitness reduction incurred through sibling competition by producing larger offspring (Parker \& Begon 1986). In Elysia stylifera, sibling competition is only likely to occur prior to hatching. The planktotrophic larvae of E. stylifera are likely to disperse far from the natal habitat; therefore, the probability that siblings will compete for planktonic food or settle in the same environment is small. However, competition for resources is likely to occur among sibling embryos within a benthic egg mass (Strathmann \& Chaffee 1984, Strathmann \& Strathmann 1995). In E. stylifera, developing embryos may compete for extra-embryonic nutrients and oxygen; although it is unclear how egg size influences the capacity of embryos to assimilate ECY or consume oxygen, both may be related to development time.

\section{Extra-embryonic nutrition and considerations of the Vance model}

For marine invertebrates, Vance (1973) partitioned the factors affecting selection on egg size into the prefeeding and feeding periods. Specifically for species with benthic development, Vance assumed that the prefeeding period is spent in the benthos (e.g. inside egg masses) and the feeding period is spent in the plankton. The first assumption of Vance's model is that there is little variation in size at metamorphosis: variations in maternal provisioning strategy are considered different means to the same end. This assumption has support from experimental and theoretical studies (Emlet et al. 1987, Sinervo \& McEdward 1988, Kohn \& Perron 1994, Hart 1995, Levitan 2000). The second assumption is that increasing egg size increases the prefeeding period, and a number of studies show empirical evidence that supports the theory 
(McLaren 1966, Lonsdale \& Levinton 1985, Kohn \& Perron 1994). The third assumption of the Vance model is that decreasing egg size increases the feeding period, supported by empirical studies with snails in the genus Conus (Kohn \& Perron 1994). Sinervo \& McEdward (1988) also found that reducing egg size increased the feeding period in accordance with Vance's model, although it should be noted that the effect was restricted to early larval stages. When the 3 components of the Vance model hold true, the generalized theory predicts that larvae metamorphose at the same size and, therefore, the nutrient deficiencies of a small egg are compensated for by increased feeding in the plankton. The reduced prefeeding period in small eggs is, therefore, offset by an increase in the feeding period.

Under the Vance model, the maternal resources of egg size and additional provisioning are not distinguished. For our proceeding discussion we distinguish between the 3 sources of maternal provisioning that influence benthic development in Elysia stylifera: a prefeeding developmental period fueled solely from egg content, followed by a period where embryos assimilate albumen fluid, and finally, by a period where ECY is consumed by larvae (ECYC period). The exact mechanism and timing for the uptake of albumen nutrients is not known; we assume that it takes place after a certain period of prefeeding development, but has ceased prior to the ECYC period. We have deliberately not called the assimilation of albumen and the ECYC period a 'feeding' period; in the Vance model and in subsequent theory, feeding specifically means the consumption of non-maternally derived nutrition, e.g. plankton. We assume that selection on egg size in E. stylifera acts as Vance described for life-history evolution in general. We also consider the early feeding stage of planktonic larvae in the Vance model analogous to the assimilation of albumen and the ECYC period within the egg mass in E. stylifera.

Although larval size was variable and dependent on extra-embryonic nutrients (see 'Maternal provisioning per offspring'), comparing the coefficients of variation of egg mass traits in Elysia stylifera shows that larval size at hatching is the least variable trait both within and among egg masses. Also, our results show that egg size and larval size were not related; therefore, in our proceeding discussion we assume that larval size at hatching is relatively constant and independent of egg size. With regards to the Vance model, it is appropriate to assume that larval size at hatching in E. stylifera is analogous to the size of juveniles at metamorphosis in the Vance model: it is constant and independent of egg size. The developmental mechanisms affecting size at metamorphosis in the Vance model are, therefore, likely to be similar to those that affect larval size at hatching in E. stylifera.

If the relationship between egg size and prefeeding period in Elysia stylifera follows theory and empirical studies, then we can expect that larvae from smaller eggs will have faster prefeeding development. The ability to develop fast has 2 clear advantages: (1) faster development reduces exposure to sources of mortality; (2) in E. stylifera, veligers that develop through the prefeeding stage faster gain first access to ECY. When capsule size is constant, larvae from smaller eggs will have a longer ECYC period. Comparatively, the prefeeding development of larger eggs will be slower, thus reducing the time larvae from larger eggs will have access to ECY; therefore, the ECYC period is reduced. This hypothesis agrees with the Vance model that predicts the feeding period increases with decreases in egg size. If the higher amount of resources in larger eggs is inversely proportional to the lower amount of resources obtained during a shorter ECYC period (and vice versa for smaller eggs), we would expect all larvae to hatch at the same size (Fig. 4), which is supported by our data.

The assimilation of albumen adds complexity to the above generalization. Increasing capsule size is likely to increase the amount of albumen assimilated and increase development time. If both capsule size and egg size are small, or both capsule size and egg size are large, we expect that the changes in development

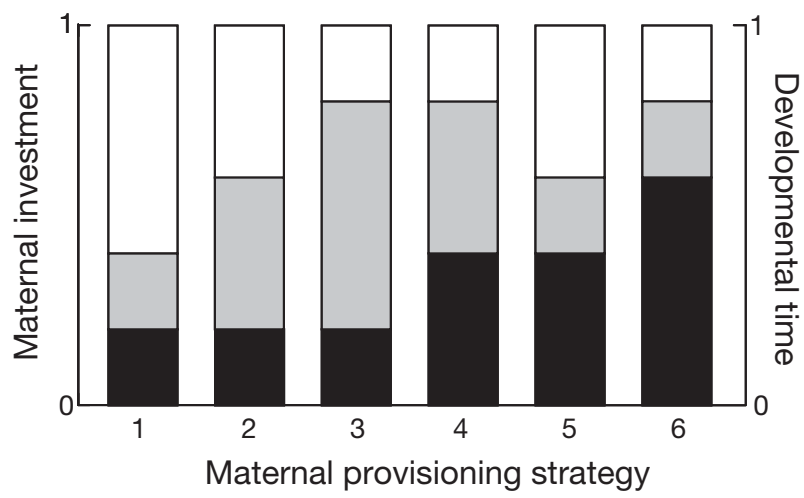

Fig. 4. Elysia stylifera. A schematic of theoretical considerations of the effect of extreme variability in resources allocation on the development time within egg masses. The $x$-axis shows 6 hypothetical egg masses that vary in the allocation of maternal resources to egg size, capsule size, and extra-capsular yolk. Total maternal investment per individual embryo is divided into egg size (black ), capsule size (grey), and amount of extra-capsular yolk available per embryo (white). Total maternal provision $=1$, where each form of provisioning varies between 0 and 1 . Total period inside the egg mass varies between 0 and 1, and is proportional to maternal investment: increasing maternal investment at a particular stage increases the developmental period of that stage, and subsequently decreases maternal investment and developmental period in the other stages. All larvae hatch at the same size and time 
prior to the ECYC period will match the previous predictions (Fig. 4). When variation in capsule size is inversely proportional to egg size, we expect that the variability in capsule size will have a greater effect on development time than egg size. This is because our results showed that larval size was dependent on capsule size and the amount of ECY per embryo, so that decreasing capsule size decreases capsular development time, but increases the ECYC period. The interdependent relationship between capsule size and the amount of ECY per embryo supports this hypothesis, because when capsule size was small, the amount of ECY increased larval size, but when capsule size was big, the amount of ECY per embryo had little effect on larval size.

\section{The constraints of oxygen within egg masses}

In addition to competition for ECY, embryos may also compete for oxygen. Increasing the number of developing embryos can reduce the amount of oxygen available to individual embryos (Strathmann \& Chaffee 1984), and oxygen limitation can retard development and produce lower quality offspring (Strathmann \& Strathmann 1995). In our study, mothers that produced more eggs also increased the size of egg masses. Oxygen may be more limited in larger egg masses, which have a lower volume-to-surface area ration and contain more embryos. Mothers could potentially compensate for prolonged development in oxygen-limited egg masses by manipulating egg size, which likely affects development time. Mothers that produced larger egg masses also produced larger eggs, but that would increase prefeeding development time (Vance 1973), thereby exacerbating the influence of oxygen limitation. However, the ECYC period would be reduced. If the ECYC period is reduced more than the prefeeding period is increased by larger eggs, then mothers may adaptively adjust egg size to reduce the benthic development time of their offspring.

The spacing of eggs within an egg mass is also a factor that can affect the amount of oxygen available to embryos (Strathmann \& Chaffee 1984). We found no relationship between the number of eggs per $\mathrm{mm}^{2}$ and egg number (egg mass size) or egg size; therefore, our data show mothers were not compensating for a potential reduction in available oxygen per embryo in large egg masses by manipulating egg size. However, eggs per $\mathrm{mm}^{2}$ was related to the both capsule size and larval size. By increasing the size of capsules that contain 1 embryo each, an inevitable consequence was that the space between each embryo increased. The increase in spacing may relieve oxygen availability constraints and allow for larger larvae to develop.

\section{CONCLUSIONS}

The provisioning strategy of Elysia stylifera allows mothers to manipulate offspring size not by varying egg size, but rather by altering capsule size and the amount of ECY available to each developing embryo. Testing our hypotheses on the role of ECY will require precise data on developmental time. However, in the context of the early Vance (1973) model and recent empirical studies, we suggest that capsule contents and ECY may be resources that compensate for reduced maternal provisioning in egg size, or each other. Extra-capsular yolk may also function as a mechanism allowing mothers to reduce exposure to benthic mortality by decreasing the prefeeding period with smaller (and faster developing) eggs, while maintaining a large larval size at hatching. Models of lifehistory evolution should incorporate extra-embryonic nutrients along with egg size and spacing, development time and offspring size at independence to better understand the complex provisioning strategies expressed by marine invertebrates with an encapsulated benthic period.

Acknowledgements. We thank D. Aguirre, N. Anderson, E. Burgess, S. Hart, A. Janisch, A. Mirams, D. Moran, M. Phillips, T. Sinclair-Taylor, E. Treml and J. Walsh, and especially N. Holmes for assisting in field collections. R.M.A was supported by an Australian Post-Graduate Award. P.J.K. was supported by the US National Science Foundation programs in Biological Oceanography (OCE 06-48606), Systematics and Biodiversity Inventories (DEB 08-17084), and the Human Resources Division (HRD 03-17772). D.J.M and this project were funded by the Australian Research Council (DPO556552).

\section{LITERATURE CITED}

Allen RM, Buckley YM, Marshall DJ (2008) Offspring size plasticity in response to intraspecific competition: an adaptive maternal effect across life-history stages. Am Nat 171:225-237

Boucher LM (1983) Extra-capsular yolk bodies in the egg masses of some tropical Opisthobranchia. J Molluscan Stud 49:232-241

Bridges TS, Heppell S (1996) Fitness consequences of maternal effects in Streblospio benedicti (Annelida: Polychaeta). Am Zool 36:132-146

Chaparro OR, Oyarzun RF, Vergara AM, Thompson RJ (1999) Energy investment in nurse eggs and egg capsules in Crepidula dilatata Lamarck (Castropoda, Calyptraeidae) and its influence on the hatching size of the juvenile. J Exp Mar Biol Ecol 232:261-274

Clark KB, Jensen KR (1981) A comparison of egg size, capsule size, and development patterns in the order Ascoglossa (Sacoglossa) (Mollusca, Opisthobranchia). Int J Invertebr Reprod 3:57-64

Clark KB, Busacca M, Stirts H (1979) Nutritional aspects of development of the sacoglossan, Elysia cauze. In: Stancyk SE (ed) Reproductive ecology of marine invertebrates. University of South Carolina Press, Columbia, SC, p 1124 
Dugan JE, Wenner AM, Hubbard DM (1991) Geographical variation in the reproductive biology of the sand crab Emerita analoga (Stimpson) on the California coast. J Exp Mar Biol Ecol 150:63-81

Emlet RB (1995) Developmental mode and species geographic range in regular sea-urchins (Echinodermata, Echinoidea). Evolution 49:476-489

Emlet RB, Hoegh-Guldberg O (1997) Effects of egg size on postlarval performance: experimental evidence from a sea urchin. Evolution 51:141-152

Emlet RB, McEdward LR, Strathmann RR (1987) Echinoderm larval ecology viewed from the egg. In: Langoux $M$, Lawrence JM (eds) Echinoderm studies, Vol 2. A. A. Balkema, Rotterdam, p 55-136

$>$ George SB (1994) Population differences in maternal size and offspring quality for Leptasterias epichlora (Brandt) (Echinodermata, Asteroidea). J Exp Mar Biol Ecol 175: 121-131

George SB, Cellario C, Fenaux L (1990) Populations differences in egg quality of Arbacia lixula (Echinodermata, Echinoidea): proximate composition of eggs and larval development. J Exp Mar Biol Ecol 141:107-118

Gosliner TM (1995) The genus Thuridilla (Opisthobranchia: Elysiidae) from the tropical Indo-Pacific, with a revision of the phylogeny and systematics of the Elysiidae. Proc Calif Acad Sci 49:1-54

Hadfield MG, Miller SE (1987) On developmental patterns of opisthobranchs. Am Malacol Bull 5:197-214

Hart MW (1995) What are the costs of small egg size for a marine invertebrate with feeding planktonic larvae? Am Nat 146:415-426

Ito K (1997) Egg-size and -number variations related to maternal size and age, and the relationship between egg size and larval characteristics in an annual marine gastropod, Haloa japonica (Opisthobranchia; Cephalaspidea). Mar Ecol Prog Ser 152:187-195

Jensen KR (1997) Sacoglossa (Mollusca, Opisthobranchia) from the Darwin Harbour area, Northern Territory, Australia. In: Hanley JR, Caswell G, Meririan D, Larson HK (eds) The marine flora and fauna of Darwin Harbour, Northern Territory, Australia, Proc 6th Int Mar Biol Workshop, Darwin, p $163-186$

Jensen K (2001) Review of reproduction in the Sacoglossa (Mollusca: Opisthobranchia). Boll Malacol 37:81-98

Kiorboe T, Sabatini M (1995) Scaling of fecundity, growth and development in marine planktonic copepods. Mar Ecol Prog Ser 120:285-298

Klussmann-Kolb A, Wagele H (2001) On the fine structure of opisthobranch egg masses (Mollusca, Gastropoda). Zool Anz 240:101-118

Kohn AJ, Perron FE (1994) Life-history and biogeography patterns in Conus. Clarendon Press, Oxford

Krug PJ (2009) Not my 'type': bet-hedging and dispersal dimorphisms in opisthobranch life histories. Biol Bull 216: 355-372

> Levin LA (1986) Effects of enrichment on reproduction in the opportunistic polychaete Streblospio benedicti (Webster) a mesocosm study. Biol Bull 171:143-160

Levin LA, Bridges TS (1995) Pattern and diversity in reproduction and development. In: McEdward LR (ed) Ecology of marine invertebrate larvae. CRC Press, Boca Raton, FL, p 148

Levitan DR (1993) The importance of sperm limitation to the evolution of egg size in marine invertebrates. Am Nat 141: $517-536$

> Levitan DR (2000) Optimal egg size in marine invertebrates: theory and phylogenetic analysis of the critical relation- ship between egg size and development time in echinoids. Am Nat 156:175-192

Lloyd MJ, Gosselin LA (2007) Role of maternal provisioning in controlling interpopulation variation in hatching size in the marine snail Nucella ostrina. Biol Bull 213:316-324

Lonsdale DJ, Levinton JS (1985) Latitudinal differentiation in embryonic duration, egg size, and newborn survival in harpacticoid copepod. Biol Bull 168:419-431

Marshall DJ, Bolton TF (2007) Effects of egg size on the development time of non-feeding larvae. Biol Bull 212:6-11

Marshall DJ, Keough MJ (2007) The evolutionary ecology of offspring size in marine invertebrates. Adv Mar Biol 53: $1-60$

> Marshall DJ, Styan CA, Keough MJ (2002) Sperm environment affects offspring quality in broadcast spawning marine invertebrates. Ecol Lett 5:173-176

> Marshall DJ, Bolton TF, Keough MJ (2003) Offspring size affects the post-metamorphic performance of a colonial marine invertebrate. Ecology 84:3131-3137

Marshall DJ, Cook CN, Emlet RB (2006) Offspring size effects mediate competitive interactions in a colonial marine invertebrate. Ecology 87:214-225

Marshall DJ, Allen RM, Crean AJ (2008) The ecological and evolutionary importance of maternal effects in the sea. In: Gibson RN, Atkinson RJA, Gordon JDM (eds) Oceanography and marine biology: an annual review, Vol 46. Taylor \& Francis, Boca Raton, FL, p 203-250

McLaren IA (1966) Predicting development rate of copepod eggs. Biol Bull 131:457-469

Moran AL, Emlet RB (2001) Offspring size and performance in variable environments: field studies on a marine snail. Ecology 82:1597-1612

> Parker GA, Begon M (1986) Optimal egg size and clutch size - effects of environment and maternal phenotype. Am Nat 128:573-592

Paul VJ, Van Alstyne KL (1988) Use of ingested algal diterpenoids by Elysia halimedae Macnae (Opisthobranchia: Ascoglossa) as antipredator defenses. J Exp Mar Biol Ecol 119:15-29

> Pechenik JA (1979) Role of encapsulation in invertebrate life histories. Am Nat 114:859-870

Pechenik JA (1999) On the advantages and disadvantages of larval stages in benthic marine invertebrate life cycles. Mar Ecol Prog Ser 177:269-297

Perron FE (1981) The partitioning of reproductive energy between ova and protective capsules in marine gastropods of the genus Conus. Am Nat 118:110-118

Quinn GP, Keough MJ (2002) Experimental design and data analysis for biologists. Cambridge University Press, Cambridge

Reiss MJ (1989) The allometry of growth and reproduction. Cambridge University Press, Melbourne

Sinervo B, McEdward LR (1988) Developmental consequences of an evolutionary change in egg size an experimental test. Evolution 42:885-899

Smolensky N, Romero MR, Krug PJ (2009) Evidence for costs of mating and self-fertilization in a simultaneous hermaphrodite with hypodermic insemination, the opisthobranch Alderia willowi. Biol Bull 216:188-199

Spight TM (1976) Hatching size and distribution of nurse eggs among prosobranch embryos. Biol Bull 150:491-499

Spight TM, Emlen J (1976) Clutch sizes of two marine snails with a changing food supply. Ecology 57:1162-1178

Strathmann RR (1985) Feeding and nonfeeding larval development and life-history evolution in marine invertebrates. Annu Rev Ecol Syst 16:339-361 
Strathmann RR (1995) Peculiar constraints on life-histories imposed by protective or nutritive devices for embryos. Am Zool 35:426-433

Strathmann RR, Chaffee C (1984) Constraints on egg masses. II. Effect of spacing, size, and number of eggs on ventilation of masses of embryos in jelly, adherent groups, or thin-walled capsules. J Exp Mar Biol Ecol 84:85-93

Strathmann RR, Strathmann MF (1995) Oxygen supply and limits on aggregation of embryos. J Mar Biol Assoc UK 75: $413-428$

Editorial responsibility: Hans Heinrich Janssen Oldendorf/Luhe, Germany
Thompson TE, Salghetti-Drioli U (1984) Unusual features of the development of the sacoglossan Elysia hopei in the Mediterranean Sea. J Molluscan Stud 50:61-63

Thorson G (1950) Reproductive and larval ecology of marine bottom invertebrates. Biol Rev Camb Philos Soc 25:1-45

Vance RR (1973) On reproductive strategies in marine benthic invertebrates. Am Nat 107:339-352

Willows RI (1987) Intrapopulation variation in the reproductive characteristics of two populations of Ligia oceanica (Crustacea, Oniscidea). J Anim Ecol 56:331-340

Submitted: March 16, 2009; Accepted: June 10, 2009

Proofs received from author(s): August 7, 2009 